\title{
Between a rock and a hard place? Not when dealing with traumatic aortic injuries!
}

\author{
Ali Khoynezhad, MD, PhD
}

\author{
From the Cedars-Sinai Heart Institute, Los Angeles, Calif. \\ Disclosures: Author has nothing to disclose with regard to commercial support. \\ Received for publication Aug 27, 2015; accepted for publication Aug 27, 2015; available ahead of print Sept 22, \\ 2015. \\ Address for reprints: Ali Khoynezhad, MD, PhD, Atrial Fibrillation Program, Cedars-Sinai Medical Center, $127 \mathrm{~S}$ \\ San Vicente Blvd, Ste A3306, Los Angeles, CA 90048 (E-mail: akhoy@cshs.org). \\ J Thorac Cardiovasc Surg 2015;150:1663 \\ $0022-5223 / \$ 36.00$ \\ Copyright (C) 2015 by The American Association for Thoracic Surgery \\ http://dx.doi.org/10.1016/j.jtcvs.2015.08.102
}

Thoracic endovascular aortic repair (TEVAR) has become the standard of care for many pathologies of the descending thoracic aorta within the past decade, and has become the preferred approach in the majority of centers ahead of traditional open surgical replacement. ${ }^{1,2}$ This is especially true for blunt aortic injuries and acute type B aortic dissection, where TEVAR - besides being less invasive-has been shown to reduce mortality and major morbidities compared with open descending aortic replacement. ${ }^{1,2}$ This significant shift in the treatment paradigm has occurred despite healthy skepticism of senior-level aortic surgeons in the field of cardiac and vascular surgery deriving from lack of longevity data, higher reintervention rates, and a new set of adverse events unique to the endovascular arena. However, our vascular surgery colleagues are fond of reminding us of analogies between coronary artery bypass grafting and percutaneous coronary intervention, comparing it to open aortic replacement and TEVAR: Most patients seem to prefer less-invasive procedures with higher a reintervention rate to more durable and established open approach with abundant of longevity and efficacy data.

In this edition of the Journal, Myers and colleagues ${ }^{3}$ present successful endografting for blunt traumatic injury of a construction worker. The location and mechanism of injury in this case report is unlike most blunt aortic injuries: The lower descending thoracic aorta had been squeezed between the T11-12 osteophyte and a metal door. Although the details of the endografting procedure are not described, TEVAR is the most appropriate targeted therapy for this patient with active aortic contrast extravasation. Postoperative recovery and return to work is typically also significantly accelerated with TEVAR, both being important aspects in the working-age and working-class population.

In today's clinical practice, cardiovascular surgeons should not feel between a rock and a hard place when taking care of patients with blunt aortic injury. TEVAR is the primary approach for all patients with a few exceptions. First,

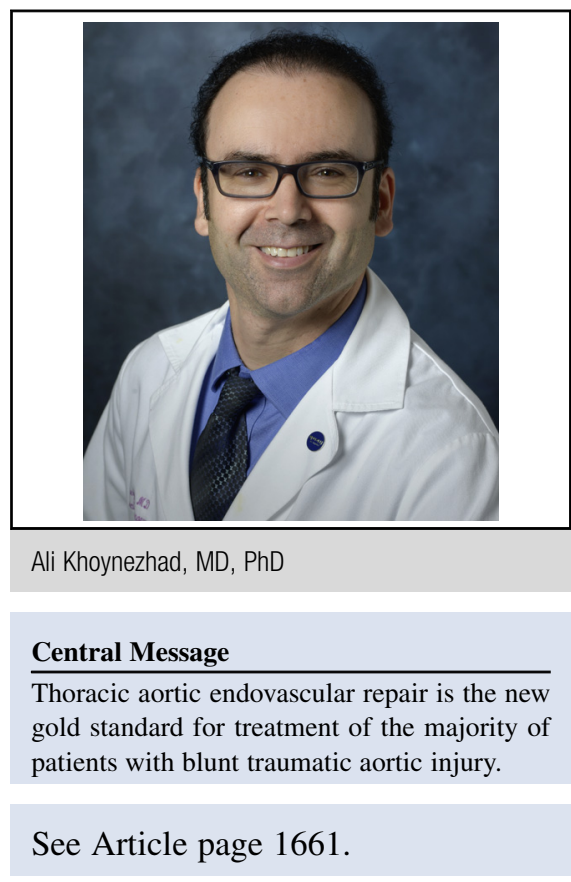

almost all patients with grade 1 blunt aortic injury should be treated medically unless there is interval worsening of the aortic pathology depicted on follow-up imaging or if there is a cerebral injury requiring elevated cerebral perfusion pressure. Second, young patients with a small (or growing) descending thoracic aorta in whom the aorta is smaller than the instructions for use for the commercially available stent grafts, should be considered for open repair.

Last but not least, all patients undergoing TEVAR need close imaging follow-up according to national interdisciplinary guidelines because complications such as migration, stent thrombosis, or retrograde dissection may occur. In future, we will have access to absorbable stent grafts that should eliminate or significantly reduce these serious complications for patients with blunt aortic injury.

\section{References}

1. Khoynezhad A, Donayre CE, Azizzadeh A, White RA. One-year results of the RESCUE trial: TEVAR for traumatic aortic injury remains a favorable therapeutic approach at midterm follow-up. J Thorac Cardiovasc Surg. 2015;149:155-61.

2. Khoynezhad A, Donayre CE, White RA. Techniques and results of endovascular management of acute complicated type b aortic dissection in North America. Rev Cardiovasc Med. 2012;13:e176-84.

3. Myers PO, Hachulla-Lemaire AL, Murith N. Traumatic thoracic aortic rupture caught between a thoracic vertebral osteophyte and a hard place. J Thorac Cardiovasc. 2015; 150:1661-2 